\title{
O novo materialismo e a crítica da atividade científica de Marx a partir das Teses ad Feuerbach
}

\author{
THE NEW MATERIALISM AND THE CRITIC OF THE CIENTIFIC ACTIVITY \\ OF MARX AFTER THE THESES AD FEUERBACH
}

\section{Douglas Rafael Dias Martins ${ }^{1}$}

\footnotetext{
1 Mestrando pelo Programa de Pós-Graduação em Filosofia da Faculdade de Filosofia e Ciências de Marília, Universidade Estadual Paulista "Júlio de Mesquita Filho" (UNESP). O presente trabalho foi realizado com apoio da Coordenação de Aperfeiçoamento de Pessoal de Nível Superior - Brasil (CAPES) - Código de Financiamento 001. E-mail: douglas_martins@hotmail.com (2underlines)

E-mail: douglas_martins@hotmail.com Lattes: http://lattes.cnpq.br/8358969022003775 Orcid: http://orcid.org/0000-0002-1465-2128
}

RESUMO: O presente artigovisa tratar do "novo materialismo" na filosofia de Karl Marx após 1845, com a produção das chamadas Teses ad Feuerbach. Nesse sentido, buscaremos expor essa nova concepção filosófica através da reformulação da relação sujeito-objeto levada a cabo por Marx, que levou o autor a uma noção crítica de ciência, distinta daquela que vigorava no pensamento europeu e posteriormente caracterizada como tradicional, bem como da crítica da metafísica da economia política. A partir dessas críticas, a concepção marxiana se apresenta como uma continuação da chamada deutschWissenschaft, uma ciência filosófica, influenciada desde Hegel, que agora coloca o modo de produção capitalista como objeto crítico que constitui uma essência histórica específica e que deve ser conhecida enquanto tomada de consciência de si e por si apontando para a necessidade de rompimento com uma atividade científica instrumentalizada pelas necessidades do desenvolvimento das relações de produção e da valorização da riqueza capitalistas. Nesse sentido, a filosofia marxiana, tendo a negatividade como motor da razão, fundamenta uma teoria crítica e revolucionária da sociedade capitalista e reivindica uma práxis emancipadora e emancipada dos interesses e finalidades da produção capitalista estrita.

Palavras-chave: Karl Marx; atividade científica; teoria crítica

ABSTRACT: The present paper seeks to investigate about the "new materialism" in the philosophy of Karl Marx after 1845, with the production of the Theses ad Feuerbach. In this sense, we are seeking to expose this new philosophical conception through the reformulationof the subject-object relation made by Marx, that take the author to a critical notion of the science, distinct of the one dominant in the european though, and further characterized as traditional, as well the critic of the metaphysic of the political economy. After those critics, the marxian conception show its self as a continuation of the so-called deutschWissenschaft, a philosophical science, influenced since Hegel, that, now, put the capitalist mode of production as a critical object that constitutes a especifical historical essence which must be known as awareness of the conscious of itself and by self pointing to the necessity to break up with an instrumentalized scientific activity by the necessities of the development of the capitalist production relations and the valorization of its wealth. In this way, the marxian philosophy, that have the negativity as the engine of the reason, substantiate a critical and revolutionary theory of the capitalist society and vindicates a emancipating and emancipated praxis of the interests and purposes of the strict capitalist production.

Keywords: Karl Marx; scientificactivity; criticaltheory 


\section{Introdução}

As chamadas Teses ad Feuerbach de Karl Marx, escritas em 1845 em Bruxelas, marcam um passo importante no desenvolvimento da filosofia do autor. Além disso, as onze teses possuem um valor simbólico, pois são uma espécie de resposta às Teses provisórias para a reforma da filosofia de Ludwig Feuerbach - que havia o influenciado até ali -, bem como um rompimento com a interpretação das "sagradas escrituras" de Hegel pelos jovens neohegelianos. Nesses marcos, apesar das poucas linhas que elas se apresentam, é perceptível as mudanças que Marx efetua na sua concepção filosófica e científica, sendo que as mesmas são uma exposição sintética de um novo materialismo e uma teoria crítica da sociedade capitalista, guardando consequências não-sistemáticas que vão desde a epistemologia até a política.

Se por um lado Marx nunca admitiu desenvolver uma filosofia sistemática como Hegel, por outro o estatuto de sua filosofia ocupa um lugar na base de sua sistematização da crítica da economia política que ocorrerá após 1845 e terá sua forma mais bem-acabada com O capital. Essa característica, que coloca a própria filosofia marxiana e marxista no centro de acalorados debates e interpretações, no entanto, se dará muito mais em virtude das próprias relações de produção capitalistas às quais a produção científica moderna se desenvolve, do que propriamente por uma mera escolha pessoal do autor. Em um debate com Proudhon, na obra Miséria da filosofiade 1847, Marx ressalta que a ciência moderna tem como uma de suas determinações a divisão técnica e social do trabalho, que por sua vez também é determinada pelas relações de produção específicas do capitalismo e do desenvolvimento das forças produtivas (MARX, 2017, p. 117).

\section{O novo materialismo de Marx após 1845 e a ciência}

Além dos novos conceitos que Marx nos apresenta após 1845, as forças produtivas e as relações de produção, se nota que a concepção da atividade científica para ele não é desligada da produção geral da sociedade - com uma neutralidade e distanciamento comumente atribuídos aos especialistas -, mas sim é dirigida pela mesma razão social. Apesar disso, o autor também não cai na defesa de um formalismo lógico no qual a ciência é responsável por analisar a manifestação fenomênica a partir de dados matemáticos e físicos que busquem traçar a utilidade e as previsões de uma "miséria do possível" - como querem alguns pragmatistas e positivistas. Na nova concepção materialista marxiana tem-se uma denúncia radical da oposição entre ser e pensar, entre entendimento e sensibilidade, perante a qual o objeto não é mais um mero elemento na qual o sujeito pode negar a si mesmo.

A relação sujeito-objeto agora é modificada em relação ao seu pensamento anterior influenciado por Feuerbach, tornando cada um dos dois enquanto categorias mais complexas e a relação entre elas mais dialetizada. Agora, o indivíduo não apenas produz o objeto como negação de si, para posteriormente, negá-lo como diferente de si e retornar a si constituindo-se como sujeito, processo que não se realiza com a alienação do trabalho e leva a uma oposição entre sujeito e objeto, como aparecia nos Manuscritos econômicofilosóficos de 1844. O objeto, por sua vez, também não é uma simples oposição ao sujeito, senão também um produto formado pela vontade de satisfação de determinadas carências do mesmo. Dessa maneira, superando as concepções filosóficas que cindem sujeito e objeto, a relação entre eles constituirá a unidade de uma relação de produção social historicamente específica. Se nos manuscritos de 1844, o sujeito não se constituía porque na medida em que ele produzia seu objeto este, por sua vez, tinha um papel deformador 
para si, a partir das Teses ad Fenerbachem 1845, Marx percebe que a atividade de trabalho alienado é parte constituinte de uma categoria lógico-social mais universal: as relações de produção.

Com a mudança dessa perspectiva, agora a filosofia marxiana considera em sua plenitude a mútua constituição entre sujeito e objeto e a totalidade da relação entre eles enquanto produção de uma razão social. Em outras palavras, Marx abandona a fundamentação da identidade entre sujeito e objeto em uma interpretação da dialética da dominação e servidão de Hegel, e passa a considerar que, de fato, o fenômeno da alienação produzido era intrínseco à determinadas relações sociais específicas. Não se trata mais, portanto, apenas de superar o trabalho alienado e recuperar seu caráter formador ao efetivar o sujeito que havia se perdido, mas sim que esse sujeito alienado é, de fato, efetivo na sociedade burguesa na medida em que as relações de produção capitalistas dependem dessa forma de trabalho para que o valor possa se valorizar. Assim, deve ser o conjunto das relações sociais que produz efetivamente essa natureza alienada do ser humano, e em particular dos trabalhadores modernos, que deve ser conhecido e abolido. A partir dessa relação que pode parecer sutil, Marx supera a teoria do sujeito, e o idealismo, que possuía nos Manuscritos e agora avança na direção de uma teoria crítica da sociedade.

O materialismo de Marx agora não ganha apenas uma base filosófica mas também um alicerce científico: se nos Manuscritos econômico-filosóficos era a atividade de trabalho que era identificada como a objetivação das indeterminadas forças essenciais humanas (MARX, 2010a, p. 111), a partir de 1845 estas últimas se tornam passíveis de análise científica ao serem transformadas em forças produtivas, sendo mais do que apenas a força de trabalho humano e que são desenvolvidas a partir de relações de produção específicas (MARX; ENGELS, 2007, p. 31). Agora a relação sujeito-objeto não se trata mais da atividade de trabalho humano que produz as mercadorias, mas tal relação representa a unidade específica entre a força de trabalho do operário e os meios de produção. Essa unidade específica, as relações de produção com as forças produtivas, por sua vez, constituem o modo de produção, ou em outras palavras, uma formação social histórica e lógica.

Em sua crítica endereçada a "todo materialismo existente até agora (o de Feuerbach incluído)", Marx, ao localizar a negação no interior das relações materiais de produção da sociedade - mais especificamente entre os processos de produção e troca -, reafirma a necessidade de se partir da percepção sensível da experiência e percorrer as mediações da mesma até seu conceito científico. Ao retomar que "na produção, os homens não agem apenas sobre a natureza," como supunha Feuerbach, "mas também uns sobre os outros" (MARX, 2010b, p. 45), Marx insinua que ao não ter avançado para além da alienação religiosa, ou melhor, compreendido a importância da categoria do trabalho como efetividade da relação sujeito-objeto, a concepção feuerbachiana passou a admitir uma separação entre objetos sensiveis e os objetos do pensamento. (MARX; ENGELS, 2007, p. 533) Para a crítica marxiana, ao não ter apreendido que a objetividade do sujeito e a subjetividade do objeto guardavam a compreensão da alienação em geral, Feuerbach não pode escapar dos limites de um materialismo contemplativo incapaz de conhecer a essência das coisas.

\section{A crítica da ciência tradicional e da metafísica da economia política}

Diferentemente de Descartes, para quem “a diversidade de nossas opiniões" tem origem na separação da substância (ou essência) do pensamento - e por isso este último "só podia ter sido inculcada em mim por uma natureza que fosse mais verdadeiramente mais perfeita do que eu", ou "numa só palavra, que fosse Deus" (DESCARTES, 1996, p. 5; 40) -, em Marx a essência humana se constitui pelo "conjunto das relações sociais" vigentes e, por isso, não seria algo eterno e dado de maneira externa à própria humanidade (MARX; ENGELS, 2007, p. 
534). Ao rejeitar a metafísica de inspiração cartesiana, a filosofia marxiana faz uma crítica à própria ontologia do capital e sua necessidade constante de revolucionar os meios de produção para manter as condições de valorização do próprio capital, ao mesmo tempo que deforma e embrutece o ser humano.

A concepção marxiana denuncia também, desse modo, a abordagem que se debruça sobre o fenômeno e mantém suas causas e pressupostos intactos, onde "todo profundo problema filosófico é simplesmente dissolvido num fato empírico" (MARX; ENGELS, 2007, p. 31). Longe de apenas negar o fenômeno empírico, Marx quer ir além da fantasmagoria do "reino autônomo" do "pensamento abstrato" produzido pelas relações sociais vigentes e encontrar a própria necessidade dessas relações de produção se constituírem de determinada maneira (MARX; ENGELS, 2007, p. 534). Será nesse desvelar da metafísica na qual repousa o desenvolvimento da economia política enquanto ciência, que Marx encontrará as estruturas e relações lógicas de autovalorização do capital enquanto relações sociais historicamente específicas. Em um caderno de 1849, intitulado Trabalho assalariado e capital, que tinha a intenção de expor o núcleo de sua teoria crítica da sociedade capitalista de maneira didática, o autor explica como se dão essas relações e deixa indicado como "os progressos técnicos da idade burguesa são inseparáveis deste tipo de funcionamento da ciência" (HORKHEIMER, 1983, p. 121):

Um capitalista só pode pôr outro capitalista em debandada e conquistar-lhe o capital vendendo mais barato. Para poder vender mais barato sem se arruinar tem de produzir mais barato, isto é, aumento tanto quanto possível a força de produção do trabalho [produtividade]. Mas a força de produção do trabalho é sobretudo aumentada por meio de uma maior divisão [técnica e social] do trabalho, por meio de uma introdução generalizada e de um aperfeiçoamento constante da maquinaria. Quanto maior é o exército de operários entre os quais o trabalho se divide, quanto mais gigantesca a escala em que se introduz a maquinaria, tanto mais diminuem proporcionalmente os custos de produção, tanto mais lucrativo se torna o trabalho.(...) Imaginemos agora essa agitação febril ao mesmo em todo o mercado mundial e compreende-se como o crescimento, a acumulação e concentração do capital têm por consequência uma divisão do trabalho, uma aplicação de nova e um aperfeiçoamento da velha maquinaria ininterruptos, que se precipitam uns sobre os outros e executados em uma escala cada vez mais gigantesca. (MARX, 2010b, p. 58; 62) (destaques do autor) (acréscimo nosso)

Tal concepção da atividade científica certamente se distancia daquela a qual Horkheimer caracterizou como teoria tradicional, onde "a dedução tal como é usual na matemática deve ser estendida à totalidade das ciências" (HORKHEIMER, 1983, p. 118). Agora, em Marx, se a atividade científica é parte das relações sociais "que são inseparáveis do crescimento do capital produtivo" (MARX, 2010b, p. 62), a forma de conhecimento não pode ser compreendida fora do conhecimento das mediação e das conexões com as mesmas, e portanto, "não têm origem em elementos puramente lógicos ou metodológicos" (HORKHEIMER, 1983, p. 121). Na mesma direção, ao criticar a suposição de Proudhon em relação à formação da indústria moderna como uma "condição de Robinson" (MARX, 2017, p. 77) - uma "robisonada”, "uma posição solitária e pouco social" criada a partir da imaginação individual e sem ligação com as necessidades lógicas e históricas reais -, Marx rejeitará em bloco as noções de formação da sociedade baseadas na concepção dos sujeitos como mônadas isoladas.

A distância de um racionalismo de tipo cartesiano e da atividade científica meramente especializada fica explícita. Apesar da diversidade de opiniões e de ramos especializados da ciência moderna, estas, no geral, se fundamentam no modo de ser da sociedade capitalista, em sua metafísica do livre-arbítrio, a qual apesar do desenvolvimento de sua diversidade de ramificações e áreas, suas relações de produção não dependem da vontade particular do produtor capitalista. Tampouco a produção depende exclusivamente da vontade do consumidor ou das demandas do mercado. "Ambos [capitalista e assalariado] são determinados por 
sua situação social, que, por sua vez, depende de toda a organização social' (MARX, 2017, p. 52) (acréscimo nosso). Entretanto, pela necessidade do próprio capital, enquanto relação social, se personificar na figura do capitalista ou da classe dominante para realizar a sua autovalorização, "as condições de existência da burguesia obrigam-na a calcular' de maneira permanente (MARX, 2010b, p. 57).

Alçada à categoria de mercadoria, o produto e objeto da atividade científica, como qualquer outra mercadoria na sociedade capitalista, tem seu valor regulado pela dominação de sua forma abstrata e não necessariamente pela sua utilidade para a sociedade ou indivíduos. Marx conclui que, "por isso, na história da sociedade [capitalista], vemos o modo de troca dos produtos se regular pelo modo de sua produção" (MARX, 2017, p. 78) (acréscimo nosso), de maneira que as atividades de reprodução da sociedade são determinadas pela forma da produção, fazendo da moderna relação entre teoria e verdade se realizar na indústria. Dessa maneira, mesmo os cálculos matemáticos e as probabilidades estatísticas seriam manifestações daquilo que Horkheimer denominou de “mecanismo social invisivel”, tendo como resultado, em meio à convergência dessa diversidade de opiniões e conhecimentos especializados com as necessidades das relações de produção, a crença de que os indivíduos agem "segundo suas decisões individuais" (HORKHEIMER, 1983, p. 123).

É precisamente nesse sentido que Marx escreverá em 1845, na segunda tese, de que "a questão de saber se ao pensamento bumano cabe alguma verdade objetiva não é uma questão da teoria, mas uma questão prática" (MARX; ENGELS, 2007, p. 533). Não se trata, portanto, de uma concepção epistemológica praticista, mas sim de afirmar que a própria atividade científica e o cientista estão ligados à estrutura social e, por isso, à medida que as relações de produção e as forças produtivas da sociedade se modificam, também deve se modificar a própria atividade de conhecimento. Para o novo materialismo marxiano, então, a dualidade ontológica moderna entre ser e pensar, expressa desde a filosofia cartesiana, não pode ser uma condição eterna e natural do ser humano, mas historicamente fundada e específica:

Os mesmos homens que estabeleceram as relações sociais de acordo com sua produtividade material produzem também os princípios, as ideias, as categorias, de acordo com suas relações sociais. Assim, essas ideias, essas categorias, são tão pouco eternas quanto as relações que elas exprimem. Elas são produtos históricos e transitórios. Há um movimento contínuo de crescimento nas forças produtivas, de destruição nas relações sociais, de formação nas ideias; de imutável só existe a abstração do movimento mors immortalis. (MARX, 2017, p. 102) (destaques do autor)

Ao defender a concepção do "serpensado" desde 44 (MARX, 2010a, p. 131), e por isso rejeitar a dissociação cartesiana entre ser e pensar, Marx assume o "modo alemão" de fazer ciência inaugurado desde Immanuel Kant e questiona os pressupostos da própria razão instrumental capitalista. O modo de proceder da ciência, agora, se constituirá por um duplo conceito: "um conceito "normal" de ciência positiva, correspondente à imagem dominante do discurso científico, e um conceito de Wissenschaft, que não renuncia ao conbecimento das essências" (BENSAÏD, 1999, p. 287). Se a razão não é uma exclusividade da ciência tradicional, para Marx, no entanto, ela não pode ser completamente abandonada uma que vez que guarda nessa razão o entendimento das relações sociais vigentes. Ao mesmo tempo que se deve considera-la como um momento necessário do conhecimento, também deve-se ir além da mesma.

Desde a filosofia de John Locke se admite a intenção de "investigar a origem, certeza e extensão do conhecimento humano" baseadas nas experiências empíricas ou no "conhecimento adquirido"(LOCKE, 1978, p. 139; 146). A preocupação central da epistemologia lockeana, dessa maneira, também se dirigia sobre a separação efetuada por Descartes e sua conclusão de que, uma vez que "para pensar épreciso existir" e, uma vez possuindo pensamentos prévios superiores e perfeitos, só poderiam ter sido inseridos por um Deus. As- 
sim, a crítica de Locke vai na direção daquilo que ele caracterizou de "verdades inatas impressas originalmente" (LOCKE, 1978, p. 147), ou seja, ideias e pensamentos que já se encontrariam anteriores a qualquer experiência sensível.

Ao afirmar que não existe nenhuma ideia geral abstrata formada originalmente na mente humana, Locke parte na busca de expor "como o entendimento procede" (LOCKE, 1978, p. 156) na apreensão das ideias como objetos do pensamento. Nessa apreensão, na qual o conhecimento se fundamenta na experiência empírica, a epistemologia lockeana acaba caindo em um aporia e um dualismo ao opor os objetos sensíveis externos e as operações internas do entendimento. Ademais, na medida em que os objetos e fenômenos sensíveis são passíveis de mudanças, tornava-se uma impossibilidade de se pensar o devir e a essência dos mesmos, e portanto, a conduta humana seria determinada apenas por convenções. Apesar de compreender esta como a única forma "adequada para levar as ideias das coisas ao entendimento" (LOCKE, 1978, p. 181), a filosofia do autor inglês não foi capaz de resolver tal dicotomia, e foi apenas com Kant que tal contradição começou a ser resolvida.

Para Kant, o sujeito seria o responsável por registrar, classificar e julgar a realidade efetiva sensível afim de conhece-la. Antes, a epistemologia kantiana deixava claro qual o seu objeto e problema ao questionar: "donde o entendimento retira a previsão segura de, segundo as suas regras, se ocupar para todo o sempre do múltiplo que é dado na sensibilidade?”. Assim, onde Locke estabelecia uma relação recíproca e harmônica entre uma pré-formação da razão e as experiências que eram dadas na sensibilidade, Kant, por sua vez, não aceitava tal disposição arbitrária. Para a concepção epistemológica kantiana, a explicação "é a de que as aparências sensiveis do sujeito transcendental já estão portanto enformadas através da atividade racional quando registradas pela percepção e julgadas com consciência." (HORKHEIMER, 1983, p. 127)

O mérito de Kant é duplo, por reafirmar a compreensão de que existe uma unidade profunda, que se manifesta como contraditória, entre o fato empírico e o pensamento teórico que depende necessariamente da atividade de cognição do sujeito; bem como que a razão subjetiva necessita de uma estrutura desenvolvida organicamente como estrutura da atividade racional. Entretanto, ao mesmo tempo que avançava parcialmente sobre a contradição entre as categorias da sensibilidade e do entendimento, a filosofia kantiana também relegava apenas ao sujeito a possibilidade de deter a razão - enquanto o objeto e "as partes principais da dedução e do esquematismo dos conceitos puros do entendimento aqui referidos trazem em si a dificuldade e a obscuridade, as quais podem estar ligadas ao fato de ele representar a atividade supra-individual(..) apenas na forma idealista de uma consciência em si" (HORKHEIMER, 1983, p. 127).

Nesse sentido, a compreensão kantiana da forma de proceder da atividade racional apreenderá a contradição geral da atividade de produção capitalista na medida em que a forma de ação dos indivíduos na sociedade também representa o modo de produção e existência de sua razão. Contudo, assim como para Kant não era possível apreender a essência dos objetos em-si, segundo ele fruto de uma dificuldade da faculdade do entendimento e de uma obscuridade da essência do objeto em-si, a produção capitalista resulta em produtos estranhos aos próprios sujeitos produtores - os trabalhadores diretos. Restava ao sujeito transcendental kantiano, desse modo, uma certa resignação e naturalização frente ao proceder do desenvolvimento técnico das relações de produção sociais vigentes, tornando-o, em meio à impossibilidade de conhecimento e transformação da essência das coisas, apto à classificação e registo da realidade sensível "como mera sequência de fatos nas ordens conceituais" (HORKHEIMER, 1983, p. 126). 


\section{A deutschWissenschaft como influência da crítica à ciência instrumental de Marx}

A concepção de Marx da atividade racional e científica, por sua vez, será tributária da filosofia crítica kantiana na medida em que também questiona os pressupostos tidos como harmônicos pela tradição empirista desde Locke entre a sensibilidade e o entendimento. Como na citação exposta mais acima, a filosofia marxiana não renega o valor do fato empírico, contudo também não é adepta de que os fenômenos filosóficos sejam dissolvidos nos mesmos. Marx não toma as relações sociais como naturais e fixas, como tampouco aceita que a manifestação fenomênica das mesmas se esgote nesse mesmo empirismo. Não apenas como herdeiro da deutschWissenschaftconsolidada com Kant, mas muito mais próximo da ciência filosófica desenvolvida por Hegel, a filosofia marxiana reafirmará a possibilidade de conhecer a essência das coisas mesmas e assumirá o problema da manifestação do mundo sensível como uma questão da produção material abstrata da sociedade. Portanto, a dificuldade apontada pela epistemologia kantiana, e a contradição mantida pela teoria da mesma, não seria "uma insuficiência subjetiva mas, ao contrário, uma insuficiência necessariamente condicionada." (HORKHEIMER, 1983, p. 128)

Assim como Descartes, Locke e Kant foram capazes de apreender certos aspectos racionais da produção capitalista e expô-las na forma de conhecimento parcial. Ao passo que a epistemologia lockeana apontava na direção de que a realidade efetiva sensível é apreendida de maneira abstrata, a concepção kantiana da atividade de conhecimento foi capaz de apontar os limites e contradições por parte do entendimento no sujeito. Para Marx, no entanto, as consequências da filosofia empirista levavam à uma rejeição da possibilidade de conhecimento da essência ou substância das coisas mesmas, entregando-se à metafísica tradicional que, em última instância, reduz o movimento e o conteúdo da realidade em categorias lógicas vazias. Em outras palavras, reduz-se a essência à mera aparência.

Já Kant, que avançava na resolução da dicotomia entre a sensibilidade e o entendimento colocada por Locke, caía no problema de transferir o problema da atividade racional apenas para o sujeito, fazendo da realidade orientada individualmente para os objetos, e cindindo sujeito e objeto ao efetivar sua relação através de representações. Não à toa, a partir dela, um pensador como Max Weber desenvolveu uma "teoria da possibilidade objetiva" afim de explicar o desenvolvimento histórico sem a necessidade de se debruçar sobre a essência das coisas, mas sim sobre representações das experiências passíveis de serem conhecidas e relacionadas pelo próprio sujeito. Agora, segundo a interpretação de Horkheimer do pensamento weberiano, "as regras da experiência,(...) não são outra coisa que formulações do nosso saber a respeito dos nexos econômicos, sociais e psicologicos", fazendo de sua teoria uma construção do "percurso provável, omitindo ou incluindo a ocorrência que deve servir para explica-lo.” (HORKHEIMER, 1983, p. 121)

Marx, de modo distinto da interpretação que Horkheimer faz da concepção weberiana, tomará o aspecto crítico da filosofia kantiana tendo em vista questionar os pressupostos da organização estrutural da sociedade e desvelar os limites e a base de suas relações de produção. Diferente da resolução de Kant sobre a dualidade entre a sensibilidade e o entendimento, a crítica marxiana não tomará a razão como neutra, eterna ou natural, mas sim como constitutiva das próprias relações de produção da sociedade - ainda que não seja um mero reflexo da mesma. Será, então, a partir da tomada da crítica, e acompanhando o desenvolvimento da deutschWissenschaft por Hegel, em que a razão é a categoria que constitui e supera a dicotomia entre a sensibilidade e o entendimento e entre sujeito e objeto, que para a filosofia marxiana "não é o trabatho somente que se define qualitativamente pelo objeto, [mas] é também o objeto que é determinado pela qualidade específica do trabalho." (MARX, 2017, p. 64) (acréscimo nosso)

Desde Hegel se expressou a noção de que a relação epistemológica entre sujeito-objeto deveria ser 
iniciada com a fenomenologização e constituição do sujeito consciente de si, marcando o percurso da consciência desde a certeza sensível até o saber absoluto na Fenomenologia do Espírito e, da mesma maneira, da superação dicotômica entre ser e pensar, ser e essência, sensibilidade e entendimento, etc. marcada na tradição moderna desde Descartes. Agora, a concepção hegeliana tambémtransforma o sentido do concei-

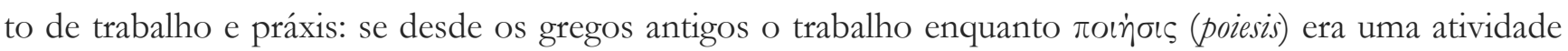
não-livre por ter como fim uma produção extrínseca - por isso mais baixa que a $\pi \varrho \dot{\alpha} \xi \iota \varsigma$ (práxis)e a $\theta \varepsilon \omega \varrho i \alpha$ (teoria) -, com os modernos ele começa a ganhar um sentido positivo mas ainda unilateral - como em Locke em que o trabalho aparece instância que serve para justificar a propriedade privada. Hegel, desse modo, vai recuperar o sentido do trabalho enquanto autoformação, atividade formadora do sujeito e produtora do objeto, e atividade que media a certeza do sujeito à verdade do objeto, ou ainda, práxis da consciência social e do Estado real enquanto prática que se pensa e pensamento que se pratica.

Assim, Hegel dá ao conceito de trabalho uma importância ímpar, ao fazer deste não apenas atividade fim da produção extrínseca (poiesis) do sujeito como também intrínseca (teoria), bem como, na mesma medida, efetivação da segunda natureza e do mundo da cultura. Desde os manuscritos produzidos no ano de 1844 Marx já havia começado a se debruçar sobre a atividade de trabalho como essa categoria de autoformação. Não à toa, nas Teses ad Feuerbach já aparecerá que "é na prática que o homem tem que provar a verdade, isto é, a realidade e o poder, a natureza interior de seu pensamento", e por isso, "a disputa acerca da realidade ou não realidade do pensamento - que é isolado da prática - é uma questão puramente escolástica." (MARX; ENGELS, 2007, p. 533) Se desde Descartes a noção de liberdade se encontrava dentro dos limites do indivíduo burguês - e por isso este aparecia, melhor em Leibniz, como uma mônada fechada em si mesmo -, com Hegel começa-se a extrapolar tal noção para além do sujeito transcendental e "a teoria torna-se realidade na medida em que ela é, para um povo, a realização de suas necessidades.” (BENSAÏD, 1999, p. 295)

Sob a direção da ciência filosófica hegeliana ${ }^{1}$, Marx, então, tomará o fio condutor da crítica negativa do trabalho, e buscará desvelar os fatos empíricos e as necessidades de um povo através de uma crítica da metafísica da economia política. Censurando Proudhon que faz das relações de produção capitalistas como as relações de todas as sociedades de todos os povos, Marx quer demonstrar que a verdade do capital como ser é a sua essência, ou seja, a autovalorização do capital. Na sociedade capitalista, portanto, as relações de produção adquirem uma autonomia própria e produzem o próprio sujeito e sua forma de consciência à medida que esse sujeito também as produz e reproduz materialmente através da abstração da atividade de trabalho e das próprias relações sociais capitalistas. Agora, a produção capitalista também aparece como um poder abstrato, que reduz todas as coisas em categorias lógicas e abstrai as particularidades de seus diferentes movimentos apresentando-lhes como puramente formais.

Da filosofia de Hegel a teoria crítica marxiana tomará a negação como motor da razão, assumindo as categorias lógicas do movimento histórico das relações sociais como sua expressão teórica e que se manifestam como "somente ideias, pensamentos espontâneos, independentes das relações reais", de modo que "a partir de então se é forçado a considerar o movimento da razão pura como a origem desses pensamentos." (MARX, 2017, p. 98) Aqui, as armas da crítica se voltam inclusive contra Hegel, já que para Marx seu método absoluto acabava por se reduzir a "uma metafísica aplicada" (MARX; 2017, p. 100). No novo materialismo de Marx, a produ-

\footnotetext{
${ }^{1}$ Daniel Bensaïd resume da seguinte maneira: “Em Diferença entre os sistemas de Fichte e Schelling, Hegel lança as bases do que se tornará, na Enciclopédia, a Ciência das ciências. As ciências humanas são superiores às da natureza. A história é o coroamento delas, pois nada vale para o homem o que não seja o objeto de sua própria tomada de consciência. O conhecimento que o espírito toma de si mesmo e por si mesmo através do conhecimento do mundo é a meta última da ciência." (BENSAïD, 1999, p. 300)
} 
ção capitalista, "enquanto relação, ela determina o seu próprio conteúdo mensurável. Da mesma forma que a essência se fenomenaliza na existência, assim também o valor se fenomenaliza no capital. Mas o mundo fenomenal é a imagem invertida do mundo em si". Assim, "a realidade enfim é "unidade da essência e da existência”, unidade do valor e do capital. É essa relação que a ciência tem por tarefa elucidar" (BENSAÏD, 1999, p. 304).

Uma vez que as categorias econômicas são tomadas apenas como "expressões teóricas, abstrações das relações sociais de produção" reais (MARX, 2017, p. 101), a fórmula lógica do movimento da produção não pode mais ser tomada como um movimento de sucessão no tempo que tem a capacidade de explicar o corpo social na qual essas diferentes relações coexistem simultaneamente. $\mathrm{Na}$ filosofia marxiana, a representação e o cálculo dos fatos empíricos na história, interpretados a partir da filosofia kantiana, não seria suficiente para superar a concepção empirista, mas sim a investigação do porquê tais princípios se manifestam em determinadas condições e relações sociais. A filosofia marxiana é, assim, uma teoria crítica da sociedade capitalista na medida em que sabe que "a consideração que isola as atividades particulares e os ramos de atividade juntamente com seus conteúdo e objetos necessita, para ser verdadeira, da consciência concreta da sua limitação", e dessa maneira, "é preciso passar para uma concepção que elimine a parcialidade que resulta necessariamente do fato de retirar os processos parciais da totalidade da práxis social” (HORKHEIMER, 1983, p. 124)

\section{Passagem e demarcações do novo materialismo filosófico de Marx desde as Teses ad Feuerbach}

Como citado na introdução do presente artigo, as Teses ad Feuerbach de Karl Marx foram produzidas em diálogo e crítica, diretas, para as Teses provisórias para a reforma da filosofia de Ludwig Feuerbach - e que o havia influenciado em sua concepção filosófica "materialista" até então. Assumindo o princípio feuerbachiano de que a verdade da filosofia deveria ter "sangue galo-germânico", tomando "do sensualismo e materialismo franceses" e da "fleuma escolástica da metafísica alemãa" (FEUERBACH, 2008, p. 12) (destaque do autor)para superar a dicotomia entre sujeito e objeto, Marx o terá como pano de fundo de toda a produção daqueles Manuscritos econômico-filosóficos. Como consequência, embora a concepção marxiana avance a de Feuerbach e de todos os pós-hegelianos - ao retomar a importância do conceito de trabalho para a relação sujeitoobjeto, ao mesmo tempo, ele também baseava a sua filosofia em uma interpretação própria da dialética da dominação e servidão de Hegel² $^{2}$.

Ao considerar que "Feuerbach é o único que tem para com a dialética begeliana um comportamento sério, crítico, e [o unico] que fez verdadeiras descobertas nesse dominio" (MARX, 2010a, p. 117) (destaque do autor), Marx reconhecia-o, naquele momento de 1844, como aquele que estabeleceu a crítica definitiva e materialista, que contribuiria para a constituição e desenvolvimento da verdadeira consciência de si do ser humano, do "ser genérico". O pressuposto da crítica feuerbachiana à Hegel, por sua vez, germinava desde Para a crítica da filosofia de Hegel que denunciava o início de sua doutrina do ser por abstrair da sensibilidade ao opor o mesmo com o nada. Em linhas gerais, Feuerbach deslocava o início da atividade filosófica do ser indeterminado, "desprovido de diferença" (FEUERBACH, 2012, p. 12)para aquele momento da consciência que Hegel havia tomado como exteriorização da essência do ser, como alienação, explicitando que a metafísica filosófica hegeliana "como expressão completa da liberdade do espírito, é, a rigor, um sistema, que não se apoia sobre a

2 Localizada no momento A verdade da certeza de si mesmo na Fenomenologia do Espírito, ou a ciência da experiência da consciência, de Hegel, a "dialética da dominação e servidão" é intitulada Independência e dependência da consciência-de-si: dominação e escravidão e vai até a Liberdade da consciência de-si.(2002, p. 142-151). 
intuição sensivel, mas sobre o pensar que se pensa a si mesmo, por isso aquilo, que é primeiro, é também último para si mesmo, e assim volta o fim para o começo." (FEUERBACH, 2012, p. 11)

Marx, pensando como transformar a cultura alemã em um Estado nacional moderno, tomava o novo sentido de alienação feuerbachianojunto a uma interpretação da dialética da dominação e servidão de Hegel e os primeiros estudos da economia política. Retomando a importância do trabalho para a superação da dicotomia sujeito-objeto, a concepção marxiana, ao mudar-se para Paris, notou que os trabalhadores deformavam-se e se tornavam mais brutalizados através relação sensível como assalariamento, a privatização dos meios de produção, a divisão do trabalho, etc. de suas atividades laborais, e o caráter formador do trabalhopretendido por Hegel não se realizava. O materialismo de Marx nesse momento, então, reafirmava o compromisso de partir da sensibilidade imediata como primeiro momento da razão e da constituição do sujeito humanista-naturalistaconsciente de si. Precisamente por isso, esse "materialismo" ainda estava submetido no interior do idealismo: analogamente à Hegel, que buscaria recuperar o caráter formador do trabalho abstrato da sociedade civil burguesa pela esfera superior de um Estadoque o pressupõe, Marx também buscaria recuperar esse caráter humano do trabalho pelo reconhecimento do trabalhador em seu produto laboralpela via externa da ação política conjunta com os filósofos socialistas.

Ao interpretar o proletariado como "o coração", "o sentido sensivel" que põe as coisas "em movimento" através do trabalho, e a filosofia como "a cabeça", "a sede do idealismo" que "põe as coisas em posição" (FEUERBACH, 2012, p. 12-13) (destaque do autor), Marx relacionava a crítica feuerbachiana com a política socialista, mas, ao mesmo tempo, via no proletariado um papel passivo e que deveria ter a sua humanidade recuperada pela filosofia socialista. Nesse momento, então, a filosofia marxiana não se caracterizava como uma teoria social, mas sim uma teoria de realização proletariado enquanto sujeito consciente de si, e nessa realização, também realizaria a emancipação humana.Contudo, no mesmo ano de 1844 ele rompe com esse esquema por conta " $d a$ revolta dos trabalhadores silesianos" (MARX; ENGELS, 2010, p. 25) (destaque do autor) e passa a destacar que "somente no proletariado encontrará o elemento ativo de sua libertação", e que, portanto, "o proletariado pode e deve libertar-se a si mesmo" (MARX; ENGELS, 2011, p. 49), marcando definitivamente o início do ponto de virada daquele novo materialismo que se consolidaria a partir das Teses ad Feuerbach. Desse modo, como buscamos deixar exposto, Marx passará a apontar a "contemplação" da relação sujeito-objeto de Feuerbach por não apreender o trabalho "como atividade humana sensível, como prática” (MARX; ENGELS, 2007, p. 533) (destaques dos autores) produtiva e reconciliação com o objeto.

Nos mesmos marcos, enquanto o "idealismo-materialista" de Feuerbach "consiste em dissolver o mundo religioso em seu fundamento mundano", o novo materialismo de Marx reivindicava para si que este "tem de ser tanto compreendido em sua contradição quanto revolucionado na prática", ou seja, a filosofia feuerbachianaalém de não ter compreendido a categoria do trabalho como "atividade prática, humano-sensivel" para reconhecer a verdade entre sujeito-objeto, também não tem condições de apreender a essência "dos indivíduos singulares e da sociedade burguesa" enquanto necessidade de ser transformada conscientemente. (MARX; ENGELS, 2007, p. 534-535) Abandonando a concepção epistemológica baseada na interpretação da dialética de dominação e servidão de Hegel, e por isso de realização do proletariado como sujeito, Marx radicaliza a noção de ciência filosófica da deutschWissenschaft ao tomar como efetiva as categorias de produção da sociedade. Para a nova filosofia materialista, agora, a atividade de trabalho é analisada cientificamente como um elemento de um conjunto de relações sociais que constituem um modo de produzir a sociedade - desde os graus de desenvolvimento técnico dos diferentes ramos da economia, da força de trabalho produtiva e improdutiva, o nível de desenvolvimento técnico-científico das forças produtivas, etc.

Contando com um fundamento filosófico, a análise crítica de Marx permite investigar cientifica- 
mente, assim, a essência humana enquanto "o conjunto das relações sociais", a "vida social" enquanto "essencialmente prática", extrapolando a análise materialista mecanicista ou contemplativa e localizando o próprio trabalho alienado como uma produção no interior de um modo de produção de "uma determinada forma de sociedade" historicamente específica. (MARX; ENGELS, 2007, p. 534) Com o novo materialismo marxiano, então, supera-se definitivamente a teoria do sujeito idealista presente nos Manuscritos econômico-filosóficos de tal maneira que o proletariado agora já é tomado em suas condições materiais de existência como efetivo, ou seja, o capital é que se realiza ao ter seu valor valorizado pela atividade de trabalho alienado dos trabalhadores enquanto poder estranho e despossessão dos mesmos, e para tanto necessita de (re)produzir seu ciclo de valorização através do trabalho assalariado. A realização na produção da abstração da relação sujeito-objeto é um meio de realização da valorização do capital, e somente apreendendo essa abstração enquanto fenômeno da essência do mesmo é possível conceber um agir emancipado e revolucionário - pervertendo e abolindoessa própria abstração.

O novo materialismo de Marx, portanto, também vai dar um novo sentido para o trabalho social como práxis na medida em que, após os trabalhadores silesianosdemonstraram que poderiam ser o elemento ativo da própria tomada de consciência de suas condições, estava claro que a existência do capital enquanto ser dependia do trabalho assalariado como forma de mediação social, e portanto, o proleteriado enquanto negativo as relações de produção capitalistas - e não um contraprincípio do modo de produção correspondente -, pode e deve liberta-se a si mesmo na medida em que também abole as relações sociais que produzem suas próprias condições materiais. Dessa maneira, agora, somente pela apreensão dos elementos abstratos sensíveis das relações materiais de produção capitalistas, como ciência filosófica, será possível compreender como o ser do "reino autônomo" (MARX; ENGELS, 2007, p. 534) do modo de produção capitalista abstrai as vontades imediatas dos indivíduos e produtores diretos - dos cientistas aos "chão de fábrica" -, transformando-os apenas em meios de valorização do capital.

Os trabalhadores da Silésia mostraram, pela "prática revolucionária", o caminho da superação da dicotomia sujeito-objeto estabelecida pela produção capitalista alienada enquanto tomada de consciência de si pela luta política e determinação consciente da produção social mediada por si mesma. Agora, longe de buscar a superação da essência contraditória da sociedade capitalista em uma esfera superior, idealista ecindida da realidade social, a filosofia materialista e a teoria crítica da sociedade capitalista de Marx conceberá que "a coincidência entre a altera[ção] das circunstâncias [sociais] e a atividade ou automodificação bumanas" só pode ser apreendida como enquanto revolução social que dissolve as próprias relações que as produzem. Por isso, diferente da atividade científica vigente naquele período, baseada em analisar fenômenos isolados oureduzir as ciências do espírito às ciências matemáticas e da natureza, Marx criticava que "os filósofos apenas interpretaram [de maneira contemplativa, dicotômica e separada] o mundo de diferentes maneiras", porém, "o que importa é transformá-lo." (MARX; ENGELS, 2007, p. 535) (destaque do autor) (acréscimo nosso)

\section{Considerações finais}

Buscamos ao longo do artigo tratar de alguns traços do novo materialismo de Karl Marx após 1845, em particular com a produção das Teses ad Feuerbach, o debate com Proudhon em Miséria da filosofia de 1847 e de um caderno intitulado Trabalho assalariado e capital de 1849. Em particular, abordamos nesse novo materialismo o tratamento de Marx sobre a atividade científica, em que o autor caracteriza tal atividade ligada às relações de produção da sociedade capitalista e sua necessidade de desenvolver as forças produtivas para manter a reprodução dos processos de valorização do valor. Nesse sentido, o desenvolvimento 
tecnológico e científico no capitalismo será instrumental - escondendo o processo de mediação social pelo qual é historicamente determinado -, porque não serve às carências da maioria da sociedade e dos indivíduos, mas sim atende às necessidades das relações de produção e reprodução capitalistas. Ainda, a produção não visa a utilidade para os indivíduos e a sociedade, mas a valorização do capital enquanto riqueza aumentada pela atividade de trabalho assalariado.

Ao ser crítico da ciência tradicional e da metafísica da economia política, Marx também reassume certa herança da deutschWissenschaftem seu novo materialismo como uma ciência filosófica que não abre mão de conhecer a essência dos fenômenos e da totalidade da produção social. Essa concepção garantirá para a filosofia marxiana uma clareza de que atividades como o trabalho, a ciência, a produção de riqueza, etc. sejam social e historicamente fundadas, ou seja, não podem ser analisadas segundo valores universais mas precisam ser consideradas segundo as particularidades da totalidade da produção social na qual se encontram. Nesses marcos, tal concepção permite a Marx, ao mesmo tempo, conhecer a essência das relações sociais capitalistas vigentes, a valorização do valor, e conceber a atividade científicae a teoria para além de sua forma como ideologia - como expressão abstrata, natural e eterna, das relações de produção dominantes -, mas sim como práxis ou prática capaz de revolucionar as relações abstratas produtoras estritas de riqueza social em relações concretas onde a produção socialconstitui-se consensualmente para a satisfação de carências humanas.

Por fim, a produção científica na concepção marxiana não deve apenas ter como função a descrição ou o cálculo dos fenômenos da realidade social que visam apenas a manutenção da produção e reprodução do capital, mas também deve levar em consideração a negatividade da essência da produção social que possibilita considerar o oposto dos fenômenos como se manifestam, e por isso, a própria abolição das condições materiais que os produzem. Em uma forma de sociedade baseada na transformação da atividade vital e produtora de riquezaem mero meio de garantir a própria existência física dos indivíduos, ou seja, na troca desigual entre tempo de força de trabalho que produz riqueza e uma certa quantidade de meios de subsistência na forma dinheiro, a filosofia materialista de Marx fundamentará uma teoria crítica da sociedade capitalista por buscar desmistificar a metafísica da economia política e abrir caminho para uma práxis social e científica emancipadora que visa romper com a dominação abstrata que as relações de produção capitalistas estabelecem.

\section{Referências}

BENSAÏD, Daniel. Marx, o intempestivo: grandezas e misérias de uma aventura crítica (séculos XIX e XX). Tradução de Luiz Cavalcanti de Menezes Guerra. Rio de Janeiro: Civilização Brasileira, 1999. 512p.

DESCARTES, René. Discurso do método. Tradução Mariana Ermantina Galvão. São Paulo: Martins Fontes, 1996. 104p.

FEUERBACH, Ludwig. Para a crítica da filosofia de Hegel. Tradução de Adriana Veríssimo Serrão. São Paulo: LiberArs, 2012. 100p.

FEUERBACH, Ludwig. Teses provisórias para a reforma da filosofia. Tradutor: Artur Mourão. Universidade da Beira Interior: Covilhã, 2008. 20p. Disponível em: http://www.lusosofia.net/textos/ 20130224-feuerbach_teses_provisorias_de_reforma_da_filosofia.pdf. Acesso em: 17 dez. 2019.

HEGEL, G. W. F. Fenomenologia do Espírito. Tradução de Paulo Menezes, com colaboração de 
Karl-HeingEfken e José Nogueira Machado. 7.ed.rev. Petrópolis: Vozes; Bragança Paulista: USF, 2002. 552p.

HORKHEIMER, Max. Teoria tradicional e teoria crítica. In: Textos escolhidos: Walter Benjamin, Max Horkheimer, Theodor W. Adorno, Jürgen Habermas. (Os pensadores) Traduções de José Lino Grünnewald... [et al.]. 2.ed. São Paulo: Abril Cultural, 1983. p. 117-154.

LOCKE, John. Ensaio acerca do entendimento humano. In: Carta acerca da tolerância; Segundo tratado sobre o governo; Ensaio acerca do entendimento humano. (Os pensadores) Tradução de AnoarAiex e E. Jacy Monteiro. 2.ed. São Paulo: Abril Cultural, 1978. p. 133-344.

MARX, Karl. Manuscritos econômico-filosóficos. Tradução, apresentação e notas Jesus Ranieri. 4. reimpr. São Paulo: Boitempo, 2010a. 192p.

MARX, K. Miséria da filosofia. Tradução José Paulo Netto. São Paulo: Boitempo, 2017. 218p.

MARX, Karl. Trabalho assalariado e capital. In: Trabalho assalariado e capital \& salário, preço e lucro. 2.ed. São Paulo: Expressão Popular, 2010b. 144p.

MARX, K; ENGELS, F. A ideologia alemã: crítica da mais recente filosofia alemã em seus representantes Feuerbach, B. Bauer e Stirner, e do socialismo alemão em seus diferentes profetas (18451846). Tradução Rubens Enderle, Nélio Schneider, Luciano CaviniMartorano. São Paulo: Boitempo, 2007.616p.

MARX, K; ENGELS, F. A sagrada família, ou, A crítica da Crítica crítica contra Bruno Bauer e consortes. Tradução, organização e notas de Marcelo Backes. 1.ed.rev. São Paulo: Boitempo, 2011. $288 \mathrm{p}$.

MARX, K; ENGELS, F. Lutas de classes na Alemanha. Tradução Nélio Schneider. São Paulo: Boitempo, 2010. 96p.

Artigo recebido em: 04 de dezembro de 2019

Artigo aceito em: 26 de dezembro de 2019 